\title{
The Syllabification System and Stress Pattern of Najdi Arabic
}

\author{
Reham Alhammad ${ }^{1}$ \\ ${ }^{1}$ Department of English, College of Science and Humanities, Majmaah University, Al-Majmaah, 11952, Saudi \\ Arabia \\ Correspondence: Reham Alhammad, Department of English, College of Science and Humanities, Majmaah \\ University, Al-Majmaah, 11952, Saudi Arabia. E-mail: r.alhammad@mu.edu.sa
}

Received: July 31, 2019 Accepted: September 5, 2019 Online Published: October 13, 2019

doi:10.5539/ijel.v9n6p116 URL: https://doi.org/10.5539/ijel.v9n6p116

\begin{abstract}
This paper discusses stress pattern in Central Najdi Arabic (CN), a dialect spoken in Riyadh, Saudi Arabia. The purpose is to determine where stress goes in this dialect, and to underline the correct ranking of constraints within the frame of Optimality Theory (OT). Final consonants in Najdi are assigned to the prosodic word, rendering heavy syllables CVC, CVVC, and CVCC to light CV, heavy CVV, and CVC respectively. Stress is found to fall on rightmost heavy syllables. If no heavy syllables are found, stress goes on the first light. Data show that the hierarchy of constraints in CN is: Culminativity, FtBIN, Trochaee, NoClash, Dep $\mu>$ SWP $>$ Extrametricality $>$ Rightmost $>$ WSP $>$ AllFtLEFT, Parse- $\sigma$.
\end{abstract}

Keywords: extrametricality, Najdi Arabic, stress assignment, stress in Arabic, optimality theory

\section{Introduction}

The focus of this paper is on Najdi, a dialect spoken in Riyadh, Saudi Arabia. There are different varieties of Najdi depending on the region where it is spoken. They are: North Najdi, Central Najdi, and South Najdi. Central Najdi (CN) spoken by Subaiee Najdi people residing in Riyadh is the focus of this paper. In specific, the paper reviews the syllabification system that is found in $\mathrm{CN}$ and shows how it is different from other dialects. It discusses the stress pattern of $\mathrm{CN}$ and determines the correct ranking of constraints within the frame of Optimality Theory (OT). By doing so, this paper aims to fill a gap within the study of Arabic Phonology.

The organization starts with a review of previous work on stress in Arabic. Section three presents the language inventory of $\mathrm{CN}$, for both consonants and vowels. In section four, the syllable structure of $\mathrm{CN}$ is presented with examples. Section five, discusses stress in $\mathrm{CN}$ and shows the correct ranking of OT constraints in the dialect. Finally, section six summarizes and concludes.

\section{Literature Review}

The concept of 'Stress' is still unsolved. There is no clear definition of stress; however, many linguists have tried to explain it in terms of pitch, duration, and loudness.

In an attempt to find out which of these three features could be used to determine stress, Fry $(1955,1958)$ developed an experimental paradigm. He manipulated some physical parameters (loudness, pitch, and duration) keeping segments the same, and asked his subjects to determine where stress goes each time a word is played. Results showed that pitch and duration were the main perceptual signs of stress compared to loudness.

Hoven (2004) discusses the properties that stressed vs. unstressed vowels have. He found that vowels of stressed syllables are usually identified as being longer and articulated more precisely than vowels in unstressed syllables. Similarly, Hulst (2010) explains that to some degree, all segments have special properties, such as: duration, spectral tilt, preciseness of articulation, and pitch. He elaborates that stressed vowels have such properties to the greatest degree whereas stressless vowels have them to a lesser degree. In fact, not only vowels have properties, there are also phonetic properties for consonants, such as: articulatory precision, longer duration, aspiration, affrication, etc.

Other linguists investigated the purpose and functions of stress. Onishi (1942) as cited in (Hasegawa, 1995) tackles this issue in his study. He argues that stress is used to either express different word meanings, or to make some parts of a word more prominent.

Most of the worlds' languages have stress, and Arabic is of no exception in this regard. Many varieties of Arabic 
allow syllables to have only two moras where the first mora is stronger than the other. This is what McCarthy and Prince (1990) refer to as 'Moraic Trochee'.

Another feature of Arabic is related to 'Extrametricality', that was first introduced by Liberman and Prince (1977). Extrametricality plays an important role in the syllabification system of Arabic. Syllables are marked extrametrical if they are ignored, and stress rules do not apply on them. Kiparsky (2003) also tackles this issue in his paper. He recalls the Prosodic Licensing Principle, suggested by Ito $(1986,1989)$, that every segment must be attached to a higher prosodic constituent. Kiparsky explains that 'floating' segments in Arabic, which are left out of the syllable and unsyllabified, are called 'semisyllables', and they are licensed to the prosodic word not to the syllable in which they occur. This is applicable to complex margins (onsets and codas), and trimoraic trochees including super heavy syllables CVCC and CVVC in what he calls the C-dialects of Arabic. Moreover, medial consonants in $\mathrm{C} \underline{\mathrm{CC}}$ clusters are also classified as semisyllables. Najdi has been found to belong to the class of $\mathrm{C}$-dialects because it shares the characteristics of C-dialects including, but not limited to, having initial clusters, and allowing medial -CCC- clusters (Algizzi, 2006) (For more information on the three different groups of C-dialects in general, and Najdi as a C-dialect in particular, See Alhammad, 2018, p. 12, 16).

In many languages, it is usually the final syllable that is marked extrametrical, for example, in Pintupi (Hansen, 1978). Interestingly, there are languages that allow heavy syllable CVC to be stressed word-medial but not word-finally, as found in Cairene dialect of Arabic where final Consonants are extrametrical (McCarthy \& Prince, 1990).

Hayes $(1979$; 1995) explains that the reason for having such cases in Arabic is that consonants in final positions are ignored causing heavy CVC to be monomoraic light CV while nonfinal CVC and CVCC structures are biomoraic. Final CVCC and CVV are counted as heavy syllables because in CVCC, only the final C is ignored while in CVV, extrametricality affects consonants only, not vowels. Hung (1993) also asserts that in all Arabic dialects, CVC is counted as heavy wherever they occur in a sentence, but word-finally.

\section{Language Inventory}

\subsection{Consonants}

Najdi has twenty-eight consonants, as shown in Table 1 below.

Table 1. Central Najdi consonantal chart

\begin{tabular}{|c|c|c|c|c|c|c|c|c|c|c|}
\hline & 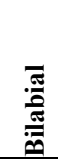 & 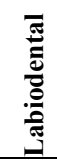 & 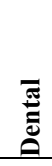 & $\frac{\grave{z}}{8}$ & 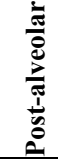 & 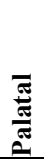 & $\frac{\grave{\pi}}{\partial}$ & $\frac{\dot{\bar{\sigma}}}{\bar{E}}$ & 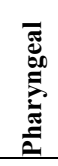 & 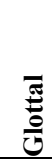 \\
\hline \multirow[t]{2}{*}{ Plosives } & $\mathrm{b}$ & & & $\mathrm{t}$ & & & $\mathrm{k}$ & $\mathrm{q}$ & & $?$ \\
\hline & & & & d & & & $\mathrm{g}$ & & & \\
\hline Pharyngealized & & & & $t^{\varsigma}$ & & & & & & \\
\hline Nasal & $\mathrm{m}$ & & & $\mathrm{n}$ & & & & & & \\
\hline \multirow[t]{2}{*}{ Fricative } & & $\mathrm{f}$ & $\theta$ & $\mathrm{s}$ & $\int$ & & & $\chi$ & $\hbar$ & $\mathrm{h}$ \\
\hline & & & ə & $\mathrm{z}$ & & & & в & $\varsigma$ & \\
\hline Pharyngealized & & & $\partial^{\varsigma}$ & $s^{\varsigma}$ & & & & & & \\
\hline Tap & & & & r & & & & & & \\
\hline Lateral & & & & 1 & & & & & & \\
\hline Approximant & $\mathrm{w}$ & & & & & $\mathrm{j}$ & $\mathrm{w}$ & & & \\
\hline
\end{tabular}

\subsection{Vowels}

There are seven vowels in $\mathrm{CN}$ : /a/, /i/ and /u/ with their long counterparts /a:/, /i:/, and /u:/, respectively, and the high front vowel /I/. Diphthongs are also found in Najdi: the vowel /a/ + glides (/aw/) as in /dawrah/ 'cycle', and (/aj/) as in /kajf/ 'how'. Watson (2007) explains that diphthongs are not represented in Arabic as diphthongal units linked to two moras /ai/ and /au/, instead they are represented as /a/ + glides $(w, j)$. She claims that diphthongs in Arabic are treated as two adjacent melodic units linked to adjacent moras. As a result, the word $/ \mathrm{kajf} /$ is treated as follows (where the last consonant is extrametrical in final position: 
(1)

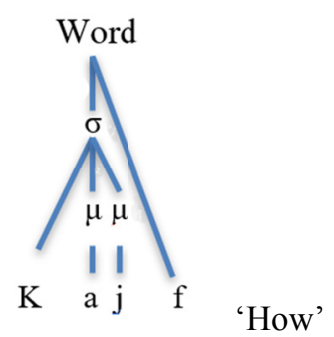

\section{Syllable Structure in $\mathbf{C N}$}

\subsection{Consonant Clusters}

Before discussing the possible syllable structures in $\mathrm{CN}$, let us review some features that affect its syllabification system. All examples provided here and in the following section are gathered by the author, a native speaker of $\mathrm{CN}$. Unlike standard Arabic and many other Arabic dialects, $\mathrm{CN}$ allows consonant clusters. In most cases, initial clusters CC- occur in $\mathrm{CN}$ due to the deletion of vowels that usually appear in careful speech, rendering CVC syllables to CC. Consider the following examples:

$$
\begin{aligned}
& (+\mathrm{V}) \quad(-\mathrm{V})
\end{aligned}
$$

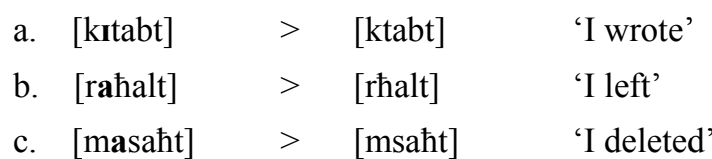

This feature makes Najdi a unique dialect compared to other varieties of Arabic (Aboud, 1979). Later on, Ingham (1994), Alghizzi (2006), and Alezetes (2007) support what Aboud claims about the occurrence of initial consonant clusters in Najdi. In fact, Kiprasky (2003) concludes that dialects that allow semisyllables to occur must have what is known as super heavy syllables, with either onset or coda cluster, or both. He describes super heavy syllables as regular syllables with adjoined semisyllables.

It is worth mentioning that the occurrence of such cluster is unrestricted in respect to the Sonority Sequencing Principle (SSP) introduced by Clements (1990). Clements claims that sonority must ascend upward towards vowels (peaks) and descend towards syllable boundaries. In case of onset clusters, the first consonant must be less sonorous than the second, which is closer to the vowel. Clements classifies vowels as the most sonorous segments, followed by glides, and then liquids. Fricatives are identified as being the least sonorous after stops. Nasals are somewhere in the middle as they are less sonorous than liquids and glides, and more sonorous than stops and fricatives.

Onset clusters in $\mathrm{CN}$ do not seem to abide by the SSP principle. There are words where the first consonant of $\mathrm{CC}$ - cluster is more sonorous than the second, as in /rbah/ 'he won', /lba:n/ 'gum'. The reverse also holds true for onset clusters as in /bra:httk/ 'it's up to you', and /blaS/ 'he swallowed'.

Coda clusters, up to two consonants, are also allowed in CN. However, unlike onset clusters, there are some restrictions for their occurrence. In his study, Alghizzi (2006) claims that coda clusters in Najdi do not occur if one of these sonorants (r, l, n, w) comes as the second consonant in a cluster, as in */gabl/ 'before' and */hibr/ 'ink', but coda clusters are possible when these sonorants start the cluster as in /harb/ 'war' and /galb/ 'heart'. This supports the claim of Haddad (1984) about having coda clusters in Arabic. He explains that for coda clusters to occur in Arabic, the first consonant must be more sonorous than the second. It is clear that coda clusters in Najdi respect the SSP scale suggested by Clement (1990) where consonants ascend upward towards vowels and descend towards the syllable boundary.

Not only clusters of onset CC- and coda -CC are found in CN. Interestingly, three consonant clusters in medial position -CCC- are also possible, which makes $\mathrm{CN}$ belong to the C-dialect category (See Algizzi, 2006). However, their occurrence is restricted to word-medial only where the first syllable of each word below is CVC, and the medial consonant in -CCC- is a part of the onset cluster of the following syllable CCVC. Here are some examples:

$$
\begin{array}{ll}
\text { a. jIfthu:n } & \text { 'they are opening' } \\
\text { b. jiktbu:n } & \text { 'they are writing' } \\
\text { c. jixtmu:n } & \text { 'they are finishing' }
\end{array}
$$


Kiprasky (2003) suggests that such consonants are semisyllables and are assigned to the prosodic word. Consider the following example:

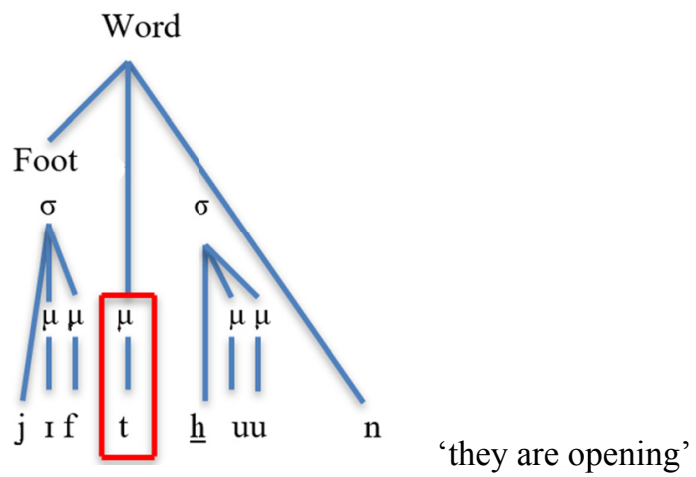

Initial-vowels are of another case. Despite what many linguists argue that words with initial vowels do not exist in Arabic (Gadoua, 2000; McCarthy, 2005; Haddad, 2005), they are accepted in the syllable structure of Najdi. Such words appear in the imperative form of certain verbs, such as the past form of the verb / $\mathrm{rab} /$ 'he drank'

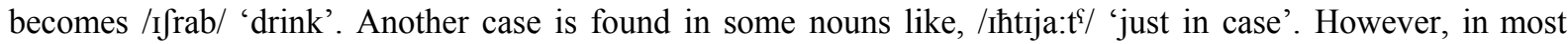
cases, they are a result of a prosthesis process that occurs when there is an onset cluster as shown in the word

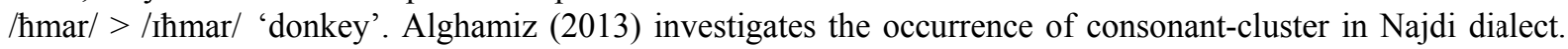
He claims that sometimes speakers resort to prosthesis as a repair tool to avoid having consonant cluster even though clusters are acceptable in their dialect. He studies ten Najdi speakers, and results show that the percentage of prosthesis in the speech of his speakers increased from $20 \%$ to $80 \%$ when producing words, like /Iћmar/ 'donkey' and /uðnu:b/ 'sins', individually compared to producing them in a fluent speech.

\subsection{Syllabification}

Heavy syllables in Arabic in general, and in CN in particular are either closed by a consonant CVC, or contain a long vowel CVV. Open syllables with short vowels are recognized as light CV. In case of final consonant clusters CVCC, the final consonant is left unsyllabified and licensed to the prosodic word. This explains why final CVC in CN counts as light, not heavy.

The minimal possible syllable structure in Central Najdi is monomoraic:

(5)
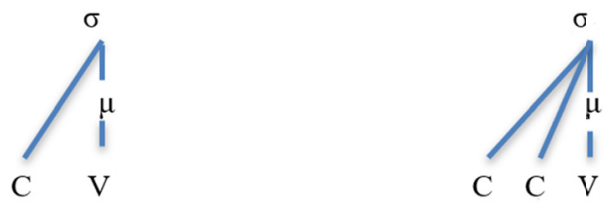

The maximal possible syllable structure is bimoraic.

(6)
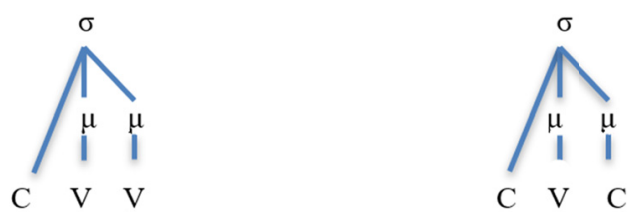

Word-final CVC syllable structure is considered light as the final consonant is ignored. Thus, CVC syllable structure only receives stress when it occurs word-medial or word-initial, but not word-finally. Hayes (1995) explains that the reason why sometimes CVC syllable structure loses stress word-finally and attracts it elsewhere is that final consonants in some languages, including Arabic, count as invisible. Thus, word-final CVC in CN is recognized as monomoraic instead of bimoraic, as shown in the following example where the final consonant is licensed to the prosodic word and not as a part of the syllable: 
(7)

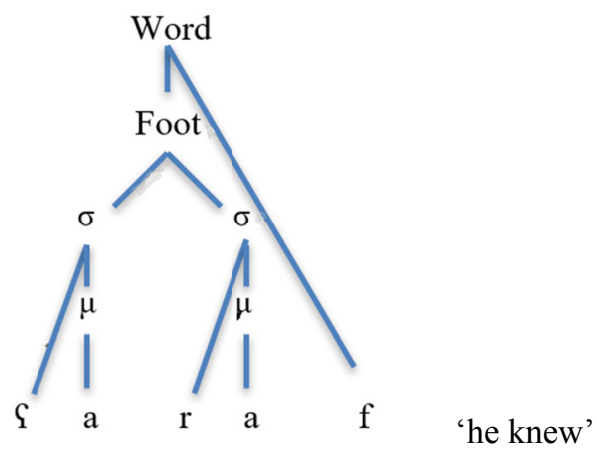

Similarly, in final CVCC and CVVC syllable structures, final consonants are always extrametrical which supports the claim that the maximal possible syllable structure in $\mathrm{CN}$ is bimoraic:

(8)

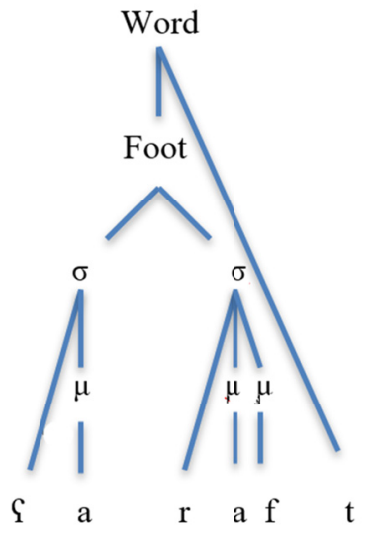

'I knew'

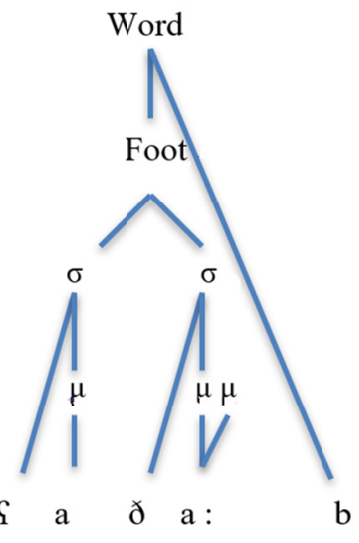

'torture'

This shows why coda clusters in $\mathrm{CN}$ are only allowed up to two consonants, while the final one is ignored, the other is treated as the coda of the syllable, a closed heavy CVC.

\section{Stress Pattern in $\mathrm{CN}$}

\subsection{CN Stress Algorithm}

(1) Primary stress falls on a final heavy (CVCC or CVVC).
a. $\mathrm{Sa}\left({ }^{\mathrm{C}} \mathrm{i}\right.$ i:)r
'juice'
b. ra('hi:)b
'lovely'
c. da('ras)t
'I studied'
d. (, mus)(ta.wa)('ja:)t
'levels'

(2) Otherwise stress the rightmost heavy syllable (up to the antepenultimate).

a. mu ('dar)ris

'teacher M'

b. mu('dar)(ri.sa)h

'teacher F'

c. (, dar)ra('sat)ni

'he taught me'

d. ji.(Yal)('lim)hum

'he is telling them'

e. (mak)('tab)ti

'my library'

f. dza ('mi:)lah

'beautiful. F'

g. (mus)('tan).gaS

'swamp'

h. (mir)('tab) t'ah

'busy'

i. ('mus)(ta.wa)

'level'

j. ('mah)(ka.ma)h

'court' 

k. ('mar)(ti.ba)h
'mattress'
1. ('mad)(ri.sa)h
'school'

(3) If there is only one heavy syllable (LH), then it must receive stress no matter where it appears:
a. $x a($ 'tam)
'he finished'
b. ga('lam)
'pen'
c. $\mathrm{s}^{\mathrm{S} a}($ ' dir $)$
'chest'

(4) Otherwise stress the leftmost light syllable.
a. ('bala)
'problem'
b. k('ta.ba)ha
'he wrote it'
c. ('s'ada)
'echo'

\subsection{Set of Constraints}

There are certain constraints in use in CN. Relevant constraints are introduced first, followed by their correct ranking in the dialect. Tableaux are used to better explain why some constraints are more important than others:

- Weight to Stress Principle (WSP): Heavy syllables must receive stress.

- Stress to Weight Principle (SWP): if a syllable is stressed, then it is heavy.

- Rightmost: Stress falls on the closest syllable to the right edge of a word.

- Depu: Do not insert a mora.

- AllFtLEFT: All feet must align to the left edge of the word.

- Parse- $\sigma$ : A syllable must be parsed in a higher prosodic structure.

- Trochee: The first part of a foot is stronger than the second.

- Extrametricality: Final consonants are licensed to the prosodic word.

- FtBINARITY: All feet must have two moras or two syllables.

- Culminativity: Every prosodic word must have at least one stress.

- Align(L,PrWd,L): A stressed light syllable must be PrWd-Initial.

- NoClash: No adjacent stresses.

Data show that the correct ranking of constraints in $\mathrm{CN}$ is:

Culminativity, FtBIN, Trochaee, NoClash, Dep $\mu>$ SWP $>$ Extrametricality $>$ Rightmost $>$ WSP $>$ AllFtLEFT, Parse- $\sigma$

Culminativity, where every word in Arabic must have stress including monosyllabic words, is an undominated constraint in CN. It is even more important than extrameticality in final consonants. Aljarrah (2002) explains that in Standard Arabic, syllables of monosyllabic words can have either two or three moras, but never one mora (light syllable). A good example of this can be seen in words like / $\mathrm{min} /$ 'who?', /umm/ 'mother' and /fii/ 'in' where words like *mi and *fi do not exist in Arabic. This is also true for $\mathrm{CN}$ in nouns like: / $\mathrm{Gam} /$ 'uncle' and /sim/ 'poison', and some verbs like: /ktab/ 'he wrote and /dras/ 'he studied'. Aljarrah argues that this minimality is due to having two highly ranked constraints in Arabic:

- $\mathrm{Lx}=\mathrm{Pr} \quad$ Every lexical word in Arabic must consist of a prosodic word

- FOOTBINARITY $\mu$ Feet must consist of two moras

Interestingly, Hayes (1995) explains that in some cases, Extrametricality is blocked if it will lead to render the entire domain of stress rules. He elaborates that in pre-optimality literature, Lx $=$ PR is formulated as a restriction on Extrametricality. In other words, the need to have stress in a word is more important than to ignore final consonants. Thus, Culminativity outranks Extrametricality in such cases. The two tableaux below show how these two constrains suggested above help to get the desired output in monosyllabic and disyllabic words in $\mathrm{CN}$ : 
(9) /Sam/ 'uncle'

\begin{tabular}{|c|c|c|c|}
\hline $\operatorname{Sam}(\mathrm{H})$ & Culminativity & FtBin $\mu$ & Extrametricality \\
\hline a. ('Sam) & & & $*$ \\
\hline b. (' $\mathrm{Ca}) \mathrm{m}$ & & $* !$ & \\
\hline c. ؟am & $* !$ & & \\
\hline
\end{tabular}

Although candidate (a) violates the Extrametricality constraint, it is still the winner in this tableau, meaning that every word in Najdi must receive stress. FtBin is also important as stressed syllables can only contain two moras. Syllables with one mora can never be stressed and this explains why candidate (b) loses in this tableau.

(10) /mita/ 'when'

\begin{tabular}{lll}
\hline mita (LL) & Culminativity & FtBin \\
\hline a. ('mita) & & $* !$ \\
b. (mi)ta & & $* !$ \\
c. mi(ta) & & $* * !$ \\
d. $(\mathrm{mI})(\mathrm{ta})$ & $* !$ & \\
e. mita & $* !$ & \\
\hline
\end{tabular}

In (10), Culminativity is not violated when a word has at least one foot. Only candidate (e) violates this constraint. Thus, the competition between all other candidates suggested the need for another constraint to account for which is the FtBin in this case.

This also explains why stress falls on final CVC in words of (LH) syllables such as, /galam/ 'pen' where Extrametricality is outranked by Culminativity as the following tableau shows:

(11) /galam/ 'pen'

\begin{tabular}{clll}
\hline ga.lam (LH) & Culminativity & FtBIN & Extrametricality \\
\hline a. ga('lam) & & & $*$ \\
b. ('ga)lam & & $* !$ & \\
c. ga.lam & $* !$ & & \\
\hline
\end{tabular}

The final consonant in (a) had to get a mora because the syllable must receive stress in order to fulfill the high-ranked constrained, Culminativity.

Just like many other Arabic dialects, feet in $\mathrm{CN}$ are moraic trochaic where they consist of two moras, the first of which is stronger than the other (Hayes, 1995). Feet can be either two light syllables or a single heavy. In fact, FtBIN is high-ranking in Najdi and must never be violated. It is even more important than Parse- $\sigma$ where a syllable must be parsed in a higher prosodic structure. To put it differently, the need to have two moras for each foot is more important than the need to have each syllable parsed into a foot. Moreover, FtBin outranks AllFtLEFT, where feet must align to the left edge of the word. Consider the following Tableau.

(12) /dza.mi:lah/

'beautiful' (singular feminine)

\begin{tabular}{llll}
\hline dza.mi:lah & FtBin & AllFtLEFT & Parse- $\sigma$ \\
\hline a. dza ('mi:)lah & & $*$ & $* *$ \\
b. (dza)('mi:)lah & $* !$ & & $*$ \\
c. (dza'mi:)(lah) & $* * !$ & & \\
\hline
\end{tabular}

Although candidate (a) violates both AllFtLEFT and Parse- $\sigma$, it is still the winner because it satisfies the high-ranking constraint FtBin while candidates (b) and (c) are ruled out due to violating FtBin.

Only heavy syllables are stressed in CN, never (LL). In fact, Najdi is not the only dialect where only heavy syllables receive stress. There are other languages that share this feature with $\mathrm{CN}$ such as, Wintu (Pitkin, 1984), Ahtna (Kari, 1990), and Swedish and Danish (Bruce, 1999). To allow for this to happen, an important constraint in Najdi must be satisfied, and that is SWP (if stressed, then heavy). Of equal importance is Dep $\mu$, which prevents the insertion of moras that could result in causing rightmost (LL) syllables to be (HL), thus become stressable. See the following example:

(13) $/$ mahkamah/ 'court'

\begin{tabular}{llll}
\hline mah.ka.mah & Dep $\mu$ & SWP & Rightmost \\
\hline a. ('mah)(kama)h & & & $*$ \\
b. (mah)('kama)h & $* !$ & & \\
\hline
\end{tabular}

Considering that rightmost syllables in $\mathrm{CN}$ receive stress, one would expect that stress falls on (kama) in example (a) above, (mah)(kama)h; however, it falls on the first part, ('mah), instead. Some other constraints 
must dominate Rightmost to cause (kama) become unstressed. These two constraints are SWP and Dep $\mu$. If we assumed that stress fell on ('kama), then according to SWP, it must be treated as a heavy (kaa). This is why Dep $\mu$ dominates SWP to prevent the insertion of moras that will cause light (ka) to be heavy (kaa), thus stressable.

Another interesting feature in $\mathrm{CN}$ is that both primary and secondary stress are found. Primary stress falls on the rightmost heavy syllable of the word while secondary falls on either first or second heavy syllable from the left edge of the word, unless if this will create a stress clash with the rightmost one:

(14) /ji. Sal.lim.hum/ 'he is telling them'

\begin{tabular}{|c|c|c|c|c|}
\hline ji.Sal.lım.hum & NoClash & Extrametricality & RightMost & WSP \\
\hline a.ji.(Sal)('lim)hum & & & & $* *$ \\
\hline b. ji(乌al)('lim)(hum) & & $* !$ & * & $* *$ \\
\hline c. ji('Cal)(lim)hum & & & $* !$ & $* *$ \\
\hline d. ji( (,al)('lim)hum & $* !$ & & & * \\
\hline
\end{tabular}

Although candidate (a) violates WSP by having two heavy syllables that are not stressed, it is still the winner in this competition. The need to satisfy other constraints is more important than to have every heavy syllable stressed in CN. This means that Extrametricality, Rightmost, and NoClash are constraints that are more important than WSP and any violation of them will cause a word to lose as shown in the above tableau. Candidate (b) loses because it violates the Extrametricality constraint by counting the final segment $/ \mathrm{m} /$ as the coda of the final syllable. Candidate (c) does not violate the Extrametricality constraint; however, stress does not fall on the rightmost foot, which is an important constraint in CN. Candidate (d), on the other hand, is ruled out because placing stress on all heavy syllables creates a stress clash, which is unacceptable in $\mathrm{CN}$.

\section{Conclusion}

An overview of the syllabification system and the stress pattern of Central Najdi is the main focus of this paper. Final consonants of $\mathrm{CN}$ are licensed to the prosodic word, which affects the syllabification process of the dialect causing final heavy CVC to be light CV. Interestingly, not only margin consonants are left unsyllabified and licensed to the prosodic word, but also medial consonant in -CCC- cluster. Stress, on another hand, is found to fall on the final heavy syllable, otherwise on the rightmost heavy. If there are no heavy syllables, then stress falls on the leftmost light syllable. To get the correct stress pattern in $\mathrm{CN}$, the following hierarchy of constraints is suggested: Culminativity, FtBIN, Trochaee, NoClash, Dep $\mu>$ SWP $>$ Extrametricality $>$ Rightmost $>$ WSP $>$ AllFtLEFT, Parse- $\sigma$.

\section{Acknowledgments.}

The author would like to thank Deanship of Scientific Research at Majmaah University for supporting this work under Project Number No. 1440-148.

\section{References}

Abboud, P. F. (1979). The verb in northern Najdi Arabic. Bulletin of the School of Oriental and African Studies, 42(03), 467-499. https://doi.org/10.1017/S0041977X0013575X

Alezetes, E. D. (2007). A markedness approach to epenthesis in Arabic speakers' L2 English. Master's thesis, University of Montana, USA. Retrieved from https://scholarworks.umt.edu/etd/270

Alghizzi, S. (2006). Najdi as a C-dialect. Unpublished master's thesis. Fresno State University, USA.

Alghmaiz, B. A. (2013). Word-initial consonant cluster patterns in the Arabic Najdi dialect. Master thesis, University of Southern Illinois, USA. Retrieved from https:/opensiuc.lib.siu.edu/theses/1078/

Alhammad, R. (2018). The Role of the syllable contact law-semisyllable (SCL-SEMI) in the coda clusters of Najdi Arabic and other languages. Doctoral dissertation, University of Wisconsin-Milwaukee, USA. Retrieved from https://dc.uwm.edu/etd/1737

Al-jarrah, R. S. (2002). An optimality-theoretic analysis of stress in the English of native Arabic speakers. Doctoral dissertation, Ball State University, USA. Retrieved from http://liblink.bsu.edu/catkey/1238739

Alqahtani, M. (2013). Sonority and epenthesis in Najdi Arabic: From An OT Perspective. In Book of Abstracts (p.1).

Bruce, G. (1999). Word stress in Swedish (Harry van der Hulst ed., pp. 554-566).

Clements, G. N. (1990). The role of the sonority cycle in core syllabification (vol. 1, pp, 283-333). Papers in laboratory phonology. https://doi.org/10.1017/CBO9780511627736.017 
Fry, D. B. (1955). Duration and intensity as physical correlates of linguistic stress. The Journal of the Acoustical Society of America, 27, 765. https://doi.org/10.1121/1.1908022

Fry, D. B. (1958). Experiments in the perception of stress. Language and Speech, 1(2), 126-152. https://doi.org/10.1177/002383095800100207

Gadoua, A. H. (2000). Consonant clusters in Quranic Arabic. Cahiers Linguistiques d'Ottawa, 28, 59-85.

Gussenhoven, C. (2004). The phonology of tone and intonation. England: Cambridge University Press. https://doi.org/10.1017/CBO9780511616983

Haddad, Y. A. (2005). Etymological itineraries in second language phonology: The case of Arabic (pp. 784-1105). Paper presented at the Second Language Research Forum.

Hansen, K. C., \& Hansen, L. E. (1978). The core of Pintupi grammar. Alice Springs, N.T: Institute for Aboriginal Development.

Hasegawa, Y. (1995). Against marking accent locations in Japanese textbooks. Japanese Language Education Around the Globe, 5, 95-103.

Hayes, B. (1979). Extrametricality in Papers on Syllable Structure, Metrical Structure and Harmony Processes. MIT Working Papers in Linguistics, 1, 77-87.

Hayes, B. (1995). Metrical stress theory: Principles and case studies. Chicago, Illinois: University of Chicago Press.

Hulst, H. V. D. (2010). Word accent: Terms, typologies and theories. A survey of word accentual systems in the language of the world. Berlin: Mouton de Gruyter, https://doi.org/10.1515/9783110198966.1.3

Ingham, B. (1994). Najdi Arabic: Central Arabian. Amsterdam. The Netherlands: John Benjamins. https://doi.org/10.1075/loall.1

Kari, J. (1990). Ahtnaa Athabaskan dictionary. Fairbanks: Alaska Native Language Center.

Kiparsky, P. (2003). Syllables and Moras in Arabic. In C. Féry \& R. Vijver (Eds.), The Syllable in Optimality Theory (pp. 147-182). Cambridge: Cambridge University Press. https://doi.org/10.1017/CBO9780511497926.007

Liberman, M., \& Prince. A. (1977). On stress and linguistic rhythm. Linguistic Inquiry, 8, 249-336.

Mccarthy, J. (2005). Optimal paradigms. Paradigms in phonological theory. Oxford: Oxford University Press. https://doi.org/10.1093/acprof:oso/9780199267712.003.0008

Mccarthy, J., \& Prince, A. (1990). Prosodic morphology and templatic morphology. In E. Mushira \& M. John (Eds.), Perspectives on Arabic linguistics II: papers from the second annual symposium on Arabic linguistics (p. 154). https://doi.org/10.1075/cilt.72.05mcc

Onishi, M. (1942). Kokugo akusento-ron. Nihongo no Akusento, 5-26.

Pitkin. H. (1984). Win/u grammar. Oakland, California: University of California Press.

Watson, J. C. (2007). The phonology and morphology of Arabic. Oxford, England: Oxford University Press.

\section{Copyrights}

Copyright for this article is retained by the author, with first publication rights granted to the journal.

This is an open-access article distributed under the terms and conditions of the Creative Commons Attribution license (http://creativecommons.org/licenses/by/4.0/). 